\title{
The Pattern of Elderly Health Tourism in Bangkok, Thailand
}

\author{
Poonsup Setsri
}

\begin{abstract}
The research study on the pattern of elderly health tourism in Bangkok. The objective is to study the pattern of elderly health tourism in Bangkok. The comparison between the behavior of the elderly with a medical tourism for the elderly. The researcher collected data using a questionnaire. The samples used in this research is. Elderly people living in the Dusit area. Of 400 people found the majority were female than male. Accounted for 18 percent Aged between 50-55 years, mostly under graduate degree. And most seniors do not have underlying disease. The study Tourism activity patterns that fit elderly were divided into 5 categories, including massage, massage and herbal sauna. Practicing meditation and ascetic. The exercise was to And a selection of healthy eating. The results showed that the Select elderly tourist activities by choosing healthy eating is the first.

The hypothesis testing period. Elderly with behavioral health care is different. To choose the form appropriate tourism activities with the elderly. Difference was statistically significant at the .05 level.
\end{abstract}

Index Terms-The elderly, health tourism, the pattern, senior.

\section{INTRODUCTION}

The current trend in the number of elderly is increasing. Due to the advancement in technology, medical and health, resulting in a mortality rate of population decline. Seniors with health problems in different ways as the body ages, it deteriorates as a result of disease to harassment by seniors with problems in the economy. There will be problems and physical health. Psychologically and socially more Thailand is mostly elderly and less educated [1], [2].

Given the lack of care from childhood, adulthood and old age such as, related and interlinked lifetime. Meanwhile, the majority of people are turning to focus on health care more to avoid the disease. This will lead to healing and the cost, according to many while tourism has been developing a model by many. So, as to attract the attention of tourists including ecotourism. The Adventure Travel Tourism, Geology Agritourism, The Historical Cultural Tourism, Our way of life of rural tourism (Health tourism).

Integrated tour, there is also another form of tourism which is becoming very popular with tourists at this time is that health tourism [3].

Manuscript received June 23, 2016; revised July 22, 2016. This work was supported in part by the research and development institute, Suan Sunandha Rajabhat University, Thailand.

Poonsup Setsri is Tourism industry subject, Faculty of Humanities and Social sciences, Suan Sunandha Rajabhat University, Thailand (e-mail: poonsub.sa@ssru.ac.th, poonsrup22@hotmail.com).
The government has set a development strategy for South Asia at the center of health (Medical Hub of Asia), which consists of Medical Services Business Health and health products and herbal Thailand [4]. Medical Services, the core business is the key. The operator is a private hospital [5]. Currently, the operator of the 256 by a private hospital that has the potential to accommodate a foreigner more than 100 and the evolution of key medical and promising growth area is to preventative medicine (Preventive Medicine. ), which focuses on prevention and health care prior to any disease. It has been increasingly popular in the United States. Countries in Europe including Thailand, Alternative Medicine. As a form of investment in associated potential The medical science to tour the country can be considered as the Company's potential in the tourism, health and business services to small, integrated (Mini Compact). By combining Medical and Wellness services together. Which is located along the shopping center or the various Office Building for the convenience of consumers and streamlines the service selection.

The researcher study pattern of elderly health tourism in Bangkok, Thailand. Objectives is to study the pattern of elderly health tourism in Bangkok. And the comparison between the behavior of the elderly with a medical tourism for the elderly.

\section{The Objective of Research}

To study the behavior of the elderly with personal activities, medical tourism model that suits the elderly.

\section{MATERIALS AND METHODS}

\section{Research Methodology}

This study used quantitative research methods. (Quantitative Research) population by 13,002. The sample used in this study. I think the formula is the formula of Taro Yamane (Taro Yamane, 1973: 125) is at a 0.05.

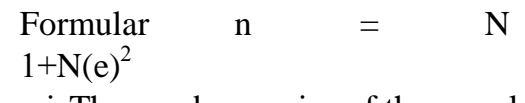

$\mathrm{n}$ isThe number or size of the sample

$\mathrm{N}$ is The number or size of population (13,002 people).

$\mathrm{e}$ isThe probability of mistakes that let happen

(in this case using 0.05) [4].

The 400samples of elderly people in Thailand Dusit, Bangkok. The researcher analyzed the data into code to process the data from the computer by using statistical software used to calculate the static and hypothesis testing as prescribed. The confidence level of $95 \%$, the difference was statistically significant at \pm 0.05 . The researchers used a statistical analysis of the data analysis by descriptive statistics (Descriptive Statistics Analysis) is used to display the frequency (Frequency) display table percentage 
(Percentage) to describe information about the feature demographic of. The sample population consisted of gender, age, education, and standard deviation (standard deviation) and averages (means) used to describe the look Interval Scale. Include the behavior of the elderly in health care. With medical tourism Forms and activities for seniors and inferential statistics (Inferential Statistics Analysis) to analyze the differences between the behavior of the elderly, including the knowledge, attitude and skills to medical tourism. Using statistical tests to find the difference $\mathrm{t}$ (T-test) in order to analyze the differences between the populations of two groups and will use static test, F (F-test) for analysis, ANOVA (One-Way. Anova) found the difference to be made out by comparing the pair. (Multiple Comparisons)With the safe Fe (Scheffe) by analyzing data to make a statistical analysis and testing statistically significant level at 0.05 .

The scope of this study were classified as follows.

1) Scope of the area this study aimed specifically at seniors living in Dusit district, Bangkok.

2) The scope of the sample population to collect data were collected from a population 400samples of older adults living in the Dusit district, Bangkok.

3) Scope and content the study of the behavior of the elderly in Bangkok with medical tourism. The study analyzes the document information theory texts on the Internet or related research and to collect questionnaires from 400 elderly residents in Dusit, Bangkok include variable.

Personal factors, including gender, age, educational level and diseases Seniors behavior are the knowledge, skills and attitude to form health tourism activities, including training for Waldorf. Exercise is a way to massage and herbal compresses. Choosing healthy eating behavior variables, including the elderly in Bangkok with medical tourism.

4) The scope of the study was to gather information. It takes about 12 months in the study between October 2015 to September 2015.

\section{RESUlts OF DATA ANALYSis}

\section{A. Data Analysis on Elderly living in Dusit, Bangkok in Thailand}

Data Analysis on Elderly living in Dusit, Bangkok in Thailand. i.e., gender, age, educational level and diseases elderly are the knowledge was show by frequency and percentage in Table I.

TABLE I: NUMER AND PERCENTAGE OF ELDERY LIVING IN DUSIT, BANGKOK IN THILAND

\begin{tabular}{ccc}
\hline Data of Personal Eldery & Number & Percentage \\
\hline Gender: Females & 236 & 59.0 \\
Age: 50-55 years & 247 & 61.8 \\
Educational: Under graduate & 342 & 85.5 \\
$\quad$ courses & 237 & 59.3 \\
$\begin{array}{c}\text { Congenital disease: Under } \\
\text { Congenital disease }\end{array}$ & & \\
\hline
\end{tabular}

The study sample seniors living in Dusit, Bangkok found that 400 people, mostly females of 236 people accounted for 59.0 percent, aged between 50-55 years of 247 people accounted for 61.8 percent, mostly under graduate courses of 342 people accounted for 85.5 percent, and most seniors are no underlying disease of 237 people accounted for 59.3 percent.

\section{B. Data on the Behavior of Elderly People in Health Care in Table II}

TABLE II: DATA ON BEHAVIOR OF ELDERLY IN HEALTH CARE

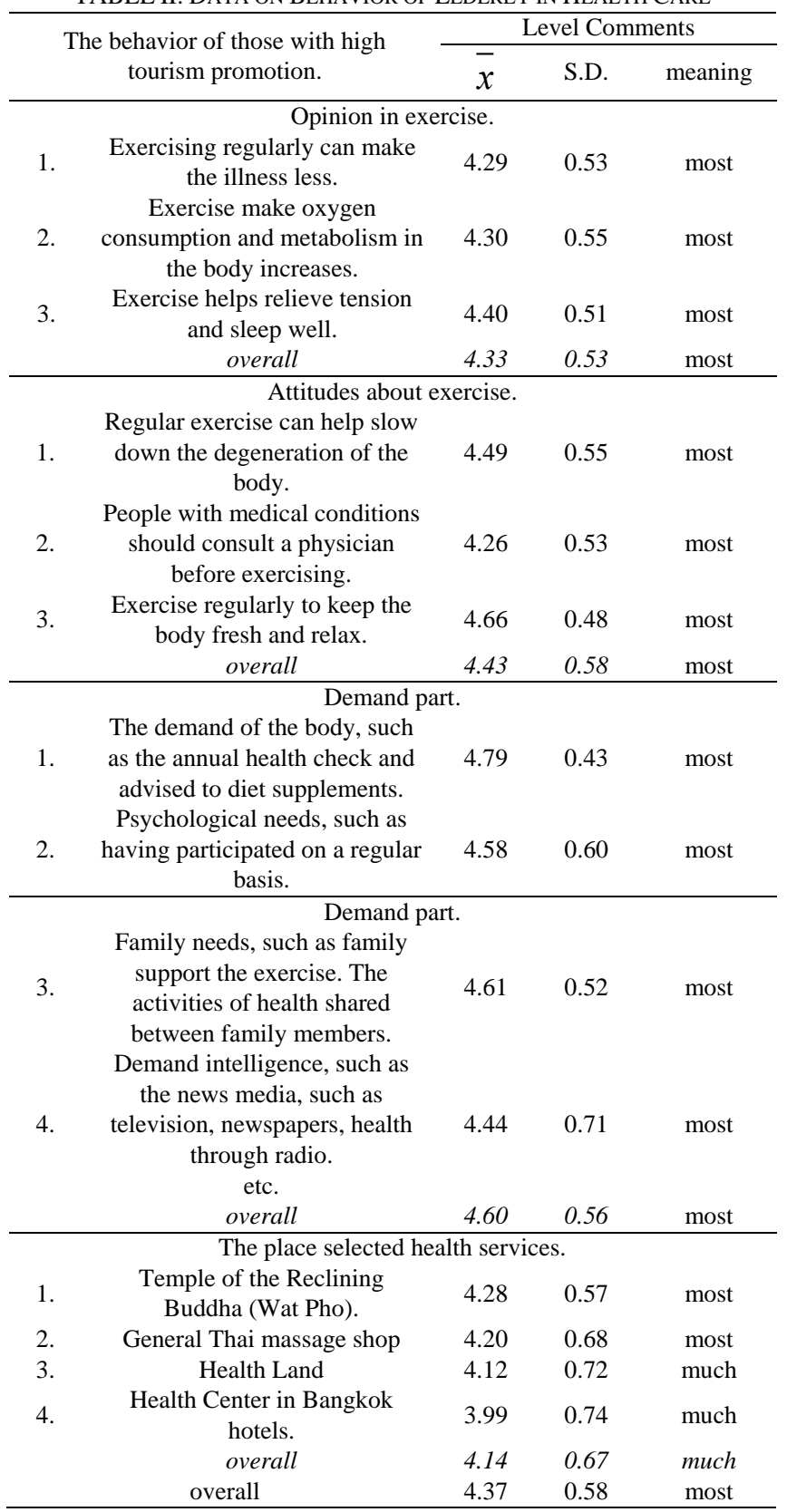

Its comments on the exercise. Found that elderly subjects with the most about exercise regularly will make the illness less. Make exercise oxygen consumption and metabolism in the body increases and exercise helps relieve tension and sleep well. The total average of 4.33 .

- Attitudes about exercise. Found that elderly subjects with most about regular exercise can help slow down the degeneration of the body. People with medical conditions should consult a physician before exercising. And regular exercise to keep the body fresh and relax. The total average of 4.43 .

- The need to exercise. Found that elderly subjects with the most demanding on the body, such as the annual health 
check. Are advised to diet supplements. Psychological needs, such as having participated on a regular basis. Family needs, such as family support the exercise. The activities of health shared between family members. And demand intelligence, such as the news media, such as television, newspapers, health through radio, with an average total of 4.60.

- Place the use of health services. Found that elderly subjects agree on the use of health services at the Temple of the Reclining Buddha (Wat Pho) General Health Land massage service and a health center in a hotel in Bangkok. The total average of 4.37 .

C. Health Tourism Activity Patterns that Fit Seniors, Divided into Five Activities include Massage and Herbal Compresses. Practicing Meditation and Ascetic. The Exercise Was a Way and a Selection of Healthy Eating. In Table III

TABLE III: DATA ON PATTERN OF TOURISM ACTIVITIES SUIBALBLE OF ELDERLY

\begin{tabular}{lcccc}
\hline \multirow{2}{*}{$\begin{array}{c}\text { Pattern of tourism activities } \\
\text { suitable for elderly. }\end{array}$} & \multicolumn{3}{c}{ Level Comments } \\
\cline { 3 - 5 } & Meditation & S.D. & meaning \\
\hline 1. & Massage with hot press & 4.18 & 0.63 & most \\
2. & Meditation & 4.36 & 0.76 & much \\
3. & Exercise & 4.50 & 0.57 & most \\
4. & Health Food & 4.67 & 0.48 & most \\
5. & overall & 4.38 & 0.60 & most \\
\hline
\end{tabular}

The study found that elderly choose activities form by choosing a healthy diet first. Average of 4.67, followed by an exercise that was like doing yoga postures inverted Dutton. Tai Chi dance moves average of 4.50 and ascetic practice meditation to calm. average of 4.36 massages like reflexology foot massage, shoulder massage - shoulder an average of 4.23 and activity patterns and the traditional herbal medicinal Thailand by highlighting the main mean of 4.18.

\section{Comparison between the Personal Behavior of Older Forms of Tourism Activities Optimum Health with the Elderly}

The study found that older people with different personal behavior. To choose medical tourism activity patterns vary. This is not consistent with the hypothesis that. Seniors with gender differences in behavior patterns to choose medical tourism activities for the elderly not different statistically significant at level. 05. And pattern of tourism activities suitable for elderly of 5 are Massage, Massage with hot press, Meditation, Good Exercise and Health food. Show that the most famous activities of women are Good Exercise (t: 2.145 sig.: 0.41), the most famous activities of men are Good Exercise (t: 1.929 sig.: 0.064). Fallow that in Table IV

TABLE IV: COMPARISON BETWEEN THE PERSONAL BEHAVIOR OF ELDERLY FORM PATTERN OF TOURISM ACTIVITIES SUITABLE

\begin{tabular}{|c|c|c|c|c|}
\hline \multirow{2}{*}{\multicolumn{2}{|c|}{$\begin{array}{l}\text { Pattern of tourism activities } \\
\text { suitable for elderly. }\end{array}$}} & \multicolumn{3}{|c|}{ t-test for Equality... } \\
\hline & & \multirow{2}{*}{$\frac{\mathrm{t}}{.490}$} & \multirow{2}{*}{$\begin{array}{c}\mathrm{df} \\
.28\end{array}$} & \multirow{2}{*}{$\begin{array}{c}\begin{array}{c}\text { Sig (2- } \\
\text { tailed)... }\end{array} \\
.628\end{array}$} \\
\hline Massage & Man & & & \\
\hline \multirow{3}{*}{$\begin{array}{l}\text { Massage with hot } \\
\text { press }\end{array}$} & Woman & .481 & 19.789 & .636 \\
\hline & Man & .893 & 28 & .380 \\
\hline & Woman & .870 & 19.436 & .395 \\
\hline
\end{tabular}

\begin{tabular}{ccccc} 
Meditation & Man & .925 & 28 & .363 \\
& Woman & .912 & 20.109 & .373 \\
\hline \multirow{2}{*}{$\begin{array}{c}\text { Pattern of tourism activities } \\
\text { suitable for elderly. }\end{array}$} & \multicolumn{3}{c}{ t-test for Equality... } \\
\cline { 3 - 5 } & $\mathrm{t}$ & $\mathrm{df}$ & $\begin{array}{c}\text { Sig }(2- \\
\text { tailed)... }\end{array}$ \\
\hline Good Exercise & Man & 1.929 & 28 & .064 \\
& Woman & 2.145 & 27.295 & .041 \\
\hline Health Food & Man & 1.615 & 28 & .118 \\
& Woman & 1.722 & 25.169 & .097 \\
\hline
\end{tabular}

***. There are statistically significant at the 0.05 level.

And the study found that Behavior of the elderly in Bangkok onto Health Tourism with different pattern of tourism activates suitable. This is consistent with the hypothesis that. Behavior of the elderly in Bangkok onto Health Tourism with different pattern of tourism activates suitable statistically significant at level 0.05 And behavior in activities of the elderly in Bangkok onto Health tourism show that the first activities is Health food, Second is Good Exercise, and the last one is Meditation in Table V

TABLE V: COMPARISON BEHAVIOR OF THE ELDERLY IN BANGKOK ONTO HEALTH TOURISM OF PATTER OF TOURISM ACTIVATES SUITABLE

\begin{tabular}{|c|c|c|c|c|c|}
\hline \multicolumn{2}{|c|}{$\begin{array}{l}\text { Pattern of tourism } \\
\text { activities suitable }\end{array}$} & \multicolumn{2}{|c|}{$\begin{array}{c}\text { Behavior of the } \\
\text { elderly in } \\
\text { Bangkok onto } \\
\text { Health Tourism }\end{array}$} & \multirow[t]{2}{*}{ F-Test } & \multirow[t]{2}{*}{ sig. } \\
\hline & & $\bar{x}$ & S.D. & & \\
\hline 1. & Massage & 4.23 & 0.63 & 6.66 & $0.00 *$ \\
\hline 2. & $\begin{array}{c}\text { Massage with } \\
\text { hot press }\end{array}$ & 4.18 & 0.76 & 6.98 & $0.00 *$ \\
\hline 3. & Meditation & 4.36 & 0.60 & 6.01 & $0.00 *$ \\
\hline 4. & $\begin{array}{c}\text { Good } \\
\text { Exercise }\end{array}$ & 4.50 & 0.57 & 6.20 & $0.00 *$ \\
\hline 5. & Health Food & 4.67 & 0.48 & 6.96 & $0.00 *$ \\
\hline
\end{tabular}

*.**. There are statistically significant at the 0.05 level.

\section{Discussions AND CONCLUSION}

The study research on the behavior of the elderly in Bangkok and found that medical tourism. Seniors with personal behavior is different. To choose medical tourism activity patterns vary. This is consistent with the hypothesis that Elderly people with different sexual behaviors in health care, different activity patterns to choose medical tourism for the elderly. Not different statistically significant level. 0.05 , consistent with the concept of the factors that contribute to a person's behavior is different. That said, the environment after birth. Influential and important person in the lives of individuals. Thus, the social differences, differences Family, the gender differences, age differences and intellectual differences. Therefore I believe the behavior of the different based on the behavior of older people in health care [6]. Found that most seniors opinions about health care that exercise helps relieve tension and sleep well. Exercise regularly makes symptoms less and exercise makes use of oxygen and metabolism in the body increases. An attitude that regular exercise can help slow down the degeneration of the body. People with medical conditions should consult a physician before exercising. And regular exercise to keep the body fresh and relax. The demand of the body, such as the annual health check was advised to diet 
supplements. Psychological needs, such as having participated on a regular basis. Family needs, such as family support the exercise. The activities of health shared between family members and the need for intelligence such has been the message of health through various media such as television, newspapers, radio and most choose to receive health services at the Temple of the Reclining Monkey pitches (Wat Pho).

When considering the appropriate form of tourism activities with the elderly found that seniors choose activities form by choosing a healthy diet is the first minor to be an exercise such as yoga. Inverted postures Dutton Dance, tai chi postures consistent with Dearie Petra International (2542) entered the study. Health needs of the elderly: a case study in Rayong study. Seniors want to get advice on health, nutrition and exercise [7]. The psychological needs most seniors want to stay close to their children. Want their children to take care of the welfare of the state or community events like the tradition and culture of the village [8].

\section{SugGestions}

The feedback from the research: medical tourism activity patterns that fit elderly found that seniors choose activities form by choosing a healthy diet, so to arrange tours for seniors. Should focus on a healthy diet is key. And activities relating to the exercise of such a right way to do yoga postures inverted Dutton. Tai Chi dance moves

Any suggestions on how to do research next time: a study on promoting market access to medical tourism for the elderly.

\section{ACKNOWLEDGMENT}

We thank you for Research and development institute, Suan Sunandha Rajabhat University to support in this research.

\section{REFERENCES}

[1] Surapong Ampanwong and Nattapon Leelawattanun. (2014). [Online]. Available: http://www.thairath.co.th/content/417799

[2] Ministry Tourism and Sports, Summary of Domestic Tourism Situation 1998-1999, Bangkok: Tourism Academic Division, 2008.

[3] K. Wannalerd, Marketing Promote Policy for Thai Healthy Business, Bangkok: Planning Policy Division, 2008.

[4] Y. Taro, Statistic: Introductory Analysis, 2ed. New York: Harper and Row, p. 125, 1973.

[5] S. Chetanont, Marketing Communication Tactics of Tourism Businesses in Preparation towards ASEAN Economic Community, 2016.

[6] P. Sujamnong, Community Sanitation, 5 ed. Bangkok: Thaiwattanapanich, 2001.

[7] N. Karmaeim, Trends to Health Tourism Behavior of People in Bangkok, Bangkok: Srinakharinwirot University, 2010.

[8] S. Petrasuwan, Requirementa Elderly Sanitation Healthy: A Case study of Rayong Province, Bangkok: Mahidol University, 1999.

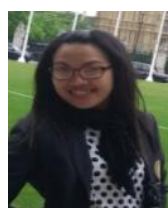

Poonsup Setsri was born on December 1, 1979. She has completed her bachelor in information system management and a master degree in tourism and hote management. She is a lecturer with Faculty of Humanities and Social Sciences, Suan Sunandha Rajabhat University, Thailand. Her interest is in tourism and hotel. 